\title{
A pilot study of a smoking cessation intervention for women living with HIV: study protocol
}

This article was published in the following Dove Press journal:

Open Access Journal of Clinical Trials

7 February 2017

Number of times this article has been viewed

\section{Sun S Kim \\ Sabreen Darwish \\ Sang A Lee \\ Rosanna F DeMarco}

Department of Nursing, College of Nursing and Health Sciences, University of Massachusetts Boston, Boston, MA, USA
Correspondence: Sun S Kim Department of Nursing, College of Nursing and Health Sciences, University of Massachusetts Boston, 100 Morrissey Boulevard, Boston, MA 02125-3393, USA

Email Sun.kim@umb.edu
Background: Prevalence of cigarette smoking is substantially higher among people living with human immunodeficiency virus (HIV) than the general population in the USA. Women living with HIV (WLHIV) who smoke are at higher risk of developing acquired immunodeficiency syndrome and have a higher mortality rate than nonsmoking WLHIV. Compared to men, women generally require more intensive counseling for smoking cessation. The primary aim of this study is to examine the acceptability and feasibility of a videoconferencing smoking cessation intervention that is tailored to the specific needs of WLHIV.

Methods: A total of 50 WLHIV will be randomized at a ratio of 1:1 to either a videoconferencing or a telephone counseling arm. Both arms have the same cessation intervention, that is, eight weekly individualized counseling sessions of 30-minute cognitive behavioral therapy plus active nicotine patches for 8 weeks. The only difference between the two arms is the delivery mode of the counseling, that is, telephone video call vs. telephone voice call. Data collection is scheduled at baseline and three follow-up points: 1, 3, and 6 months from the target quit day. Data will be analyzed using STATA 14. The primary outcome is a 6-month prolonged abstinence. Home-based salivary cotinine test will be conducted to verify self-reported smoking abstinence using a NicAlert ${ }^{\mathbb{R}}$ test strip, while a research coordinator monitors the whole process by a telephone video call. Conclusion: The study is a two-arm parallel-group pilot clinical trial of a smoking cessation intervention. It attempts to examine whether videoconferencing smoking cessation intervention will be acceptable and feasible for WLHIV and will yield a better cessation outcome than telephone counseling intervention. Findings may have the potential to identify effective intervention strategies that will reduce and eliminate health disparities in tobacco control among WLHIV.

Keywords: HIV, women, smoking cessation, videoconferencing, biochemical validation

\section{Background}

Females are at higher risk of becoming human immunodeficiency virus (HIV) positive than males due to biologic vulnerabilities, low socioeconomic status, dominant sexual practices of males, and epidemiologic factors. ${ }^{1-4}$ For example, the risk of being infected with HIV during unprotected sex is two to four times greater for females than for males. ${ }^{3,4}$ Women of color, particularly African American women in the USA, have been hard hit and represent the majority of women living with the disease and women newly infected, followed by Latinas. ${ }^{5}$ People living with HIV now live longer than ever before due to the use of highly active antiretroviral therapy (HAART). However, the burden of non-acquired immunodeficiency syndrome-related health problems such as lung diseases, cardiovascular diseases, and cancers has considerably increased and smoking is a profound cause of the problems. ${ }^{6-12}$ 
People living with HIV are far more vulnerable to lung diseases such as bacterial community-acquired pneumonia, pulmonary tuberculosis, Pneumocystis jiroveci pneumonia, and chronic obstructive pulmonary disease (COPD). ${ }^{11,12}$ COPD is an independent risk factor for high mortality in people living with HIV, and current cigarette smoking plays a significant role in its development irrespective of HAART use. ${ }^{11}$ Therefore, smoking cessation is crucial to reduce the high mortality rate of the population. Nevertheless, people living with HIV smoke cigarettes substantially at higher rates than the general population, that is, $40 \%-80 \%$ vs. $19 \%$. $^{13,14}$ Unlike the substantial difference in smoking prevalence that is generally found between the general female and male populations, women living with HIV (WLHIV) smoke at rates similar to those of their male counterparts.

Based on a systematic review of smoking cessation studies, people living with HIV prefer telephone-based smoking cessation interventions to clinic- or community-based ones. ${ }^{15}$ Researchers speculated that their preference for telephone interventions might be related to many barriers to accessing other delivery modes such as transportation, housing instability, and HIV-related stigma. However, the rates of abstinence achieved by people living with HIV who received telephone counseling were relatively low at $6 \%-9 \%$ and the majority of the participants were males. ${ }^{16,17}$ People living with HIV are more likely to quit smoking if they are married, older, or employed, or have a low level of nicotine dependence or no mood disturbance. ${ }^{18-20}$ These predictors of smoking cessation are similar to those found in the general population. On the other hand, predictors that are specific to people living with HIV include HAART use and CD4 cell count; yet, findings are inconsistent. ${ }^{18-20}$

There are substantial gender differences in smoking behavior in terms of nicotine dependence and outcomes of smoking cessation. For example, men are more likely to be heavy smokers and more nicotine dependent compared to women. ${ }^{21,22}$ Men are, however, more likely to succeed in quitting, especially when treated with nicotine replacement therapy (NRT). ${ }^{23-27}$ Women more frequently report that smoking helps them control stress and negative mood and manage their weight, and are more likely to relapse to smoking after a quit attempt. ${ }^{27-31}$ Accordingly, a meta-analysis of smoking cessation studies reported that women in general require more intensive counseling support for quitting than their male counterparts. ${ }^{25}$ As a relative comparison, Korean women smokers valued the support that they received from their therapists more than their male counterparts. ${ }^{32}$ The women stated that recalling the images of the therapists who showed genuine interest in their health was very helpful for them to resist smoking temptations.

Similar to Korean American women, videoconferencing cessation counseling could be a good alternative to telephone one for WLHIV because face-to-face interaction will facilitate therapeutic alliance with their therapists. Only three studies of a videoconferencing smoking cessation intervention were identified, but none of these studies included WLHIV. $^{32-34}$ Two studies were conducted in the USA: one on Korean American women and the other one on general smokers in primary care clinics. ${ }^{32,33}$ Both studies found no differences in videoconferencing and telephone counseling cessation interventions. In the study with Korean American women, however, cotinine-confirmed abstinence rate was $10 \%$ higher among Korean women who received a videoconferencing intervention than among those who received a telephone counseling intervention (40\% vs. 30\%). The third study was conducted in Canada and reported that videoconferencing (telehealth) smoking cessation intervention was as effective as in-person one (26\% vs. $28 \%){ }^{34}$

\section{Research aims}

There is an urgent need to develop effective and accessible smoking cessation programs for WLHIV, and the present study is a pilot clinical trial as part of an effort to develop such a program. The primary aim of the present study is to test the acceptability and feasibility of a videoconferencing smoking cessation intervention for WLHIV. The rate of enrollment among those who make the initial contact for the study and the rate of retention until the last follow-up assessment will be recorded. The secondary aim of the study is to estimate an effect size by comparing the relative effectiveness of a videoconferencing cessation intervention with a telephone counseling cessation intervention for WLHIV. The rates of 6-month abstinence will be compared between the two delivery modes: telephone video call vs. telephone voice call. In addition, the feasibility of a remote salivary cotinine test will be examined. As smoking behavior is increasingly stigmatized, participants in a smoking cessation study are likely to underreport their smoking, especially when they relapse to smoking after the intervention. ${ }^{35}$ Therefore, a biochemical test is crucial to verify self-reported abstinence.

\section{Research method Design overview}

Figure 1 provides an overview of the study. It is a 2-arm, parallel-group randomized controlled trial that will be conducted with a convenience sample of 50 women who have 


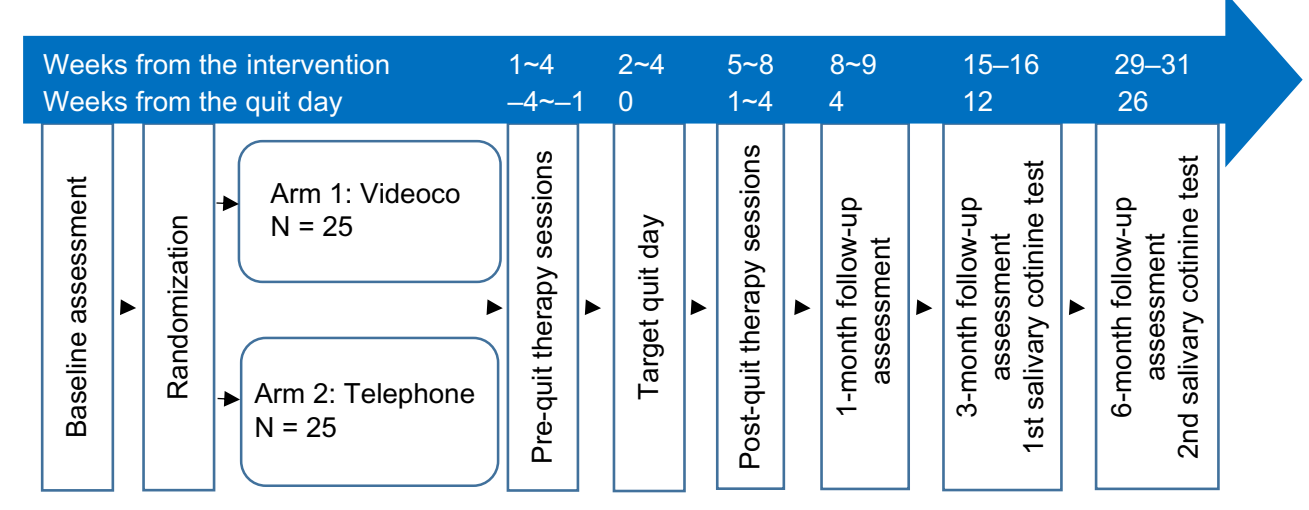

Figure I Flowchart of the study.

been diagnosed with HIV and are residing in a community. Using a personal network and Craigslist.com, participants are currently recruited offline and online across the nation. WLHIV will be encouraged to call the contact number that is provided in a study flier if they want to quit smoking. Once enrolled into the study, they will be randomized at a ratio of $1: 1$ to either the videoconferencing or the telephone counseling arm using a computer-generated random number. Participants in both arms will recieve eight weekly counseling sessions of 30-minute cognitive behavioral therapy in conjunction with active nicotine patches for 8 weeks. The study was approved by the Institutional Review Board of the University of Massachusetts Boston, and a written informed consent form will be obtained at baseline data collection.

\section{Power and sample size}

This study aims to establish a preliminary effect size of a video call smoking cessation intervention compared to a telephone call smoking cessation intervention. For pilot studies, it was suggested that 24 subjects per arm generally yield a near-accurate estimate of an effect size. ${ }^{36}$ Thus, we will recruit a total of 50 WLHIV, that is, 25 in each arm, in this study.

\section{Inclusion and exclusion criteria for participation}

Participants are currently recruited utilizing personal networks of health care providers who work for people with acquired immunodeficiency syndrome/HIV and by advertising the study on free websites such as Craigslist. To participate in the study, the following criteria need to be met: women who 1) are able to speak English; 2) self-report the diagnosis of HIV infection with a supplementary document; 3) are between the ages of 18 and 75;4) have been smoking at least five cigarettes a day for the past 6 months; 5) have an access to a video call application such as Skype,
Imo, Tango, and Face Time; 6) are willing to quit smoking within the next 4 weeks from the baseline assessment; and 7) agree to use an approved form of birth control (e.g., oral medications, condoms, and intrauterine devices) during the study period. Individuals will be excluded if they: 1) are not able to speak English; 2) are pregnant or lactating; 3) have an active skin disease or serious alcohol use problems $(\geq 26$ on the Alcohol Use Disorders Identification Test); 4) self-report currently receiving treatment for a serious mental illness (e.g., schizophrenia and bipolar disorder); or 5) are currently using any illegal substances excluding marijuana.

\section{Recruitment procedure}

When prospective participants contact the research team by calling in, a brief screening interview will be conducted using the questions listed in Table 1 . If the prospective participants are found to be eligible, they will receive an envelope enclosed with a cover letter, informed consent form, baseline research questionnaire, smoking log sheet, and self-addressed stamped envelope for a return mail. The cover letter provides instructions as to where to sign the consent form, how to complete the research questionnaire, and how to return them to the research team. The returned research questionnaire will be checked for errors and missing values and will be completed by subsequent telephone interviews or additional mailings. Once baseline assessment will be completed, participants will be informed about their group allocation and asked to schedule eight weekly counseling sessions. Those assigned to the video arm will be assisted with installation of a video call web application, if they have little or no experience using the application.

\section{Randomization process}

All participants who provide a signed consent form will be assigned to either a video or a telephone arm using a block 
Table I Scripted interview guide for screening

\begin{tabular}{|c|c|c|}
\hline No. & Screening question & Correct answer \\
\hline I & Can you speak English? & Yes \\
\hline \multirow[t]{3}{*}{2} & Have you been diagnosed with HIV infection? & Yes \\
\hline & Do you know your CD4 cell count and viral load? (This question is asked as a way to verify HIV infection.) & Yes \\
\hline & What are they? & \\
\hline 3 & $\begin{array}{l}\text { What kind of medications are you currently taking for HIV infection? (This question is asked as a way to } \\
\text { verify HIV infection.) }\end{array}$ & Any HIV medications \\
\hline 4 & How old are you? & $18-75$ \\
\hline 5 & How many cigarettes on average have you been smoking a day? & $\geq 5$ cigarettes \\
\hline 6 & How long have you been smoking daily? & $\geq 6$ months \\
\hline 7 & Are you willing to quit smoking within the next 4 weeks? & Yes \\
\hline 8 & Do you have any active skin disease? & No \\
\hline 9 & Have you had emotional complications such as feeling anxious and depressed around quitting smoking? & No \\
\hline 10 & $\begin{array}{l}\text { Do you currently receive treatments (counseling and pharmacotherapy) for any of these conditions: alcohol } \\
\text { use disorder, schizophrenia, schizoaffective disorder, and bipolar disorder? }\end{array}$ & No \\
\hline 11 & Have you ever attempted to kill yourself within the past 10 years? & No \\
\hline 12 & Do you currently use any illegal substances except marijuana (weed)? & No \\
\hline 13 & Are you pregnant or lactating? & No \\
\hline 14 & $\begin{array}{l}\text { Will you agree to use birth control pills or devices during the study period if you are between the ages of I } 8 \\
\text { and } 50 \text { and sexually active? }\end{array}$ & Yes \\
\hline 15 & Do you have access to a smartphone or computer with an Internet connection? & Yes \\
\hline
\end{tabular}

Abbreviation: HIV, human immunodeficiency virus.

randomization procedure. The procedure was carried out by first dividing numbers (1-50) into two blocks (1-25 and 26-50) and then randomly assigning the numbers in each block into the two arms (video and telephone). Each number assigned to the video arm was transferred to a small paper with the letter "V" and each number assigned to the telephone arm was with the letter " $T$ ". The paper was folded and placed in a small envelope that had the same random number outside. The envelope then was sealed and has been stored in a desk drawer. When an individual is screened and ready to be assigned, the envelope will be torn off and the person will be randomized based on the letter ( $\mathrm{V}$ or $\mathrm{T}$ ) written in the paper. The main purpose of this randomization is to assure balance between the two arms and complete blindness of both arms to participants and researchers.

\section{Interventions}

Counseling content was primarily drawn from a cognitive behavioral therapy foundation, which is guided by Bandura's Social Cognitive Theory. ${ }^{37}$ Problem-solving and skills training techniques resisting smoking temptations will be emphasized during each counseling session. ${ }^{38}$ Participants in both arms, irrespective of group allocation, will receive the same cessation counseling that consists of eight 30-minute weekly sessions (Table 2). Two therapists will provide the intervention. The first author is scheduled to provide counseling to 13 participants in each arm (a total of 26 participants) and the second author to the remaining 12 participants in each arm (a total of 24 participants). They are not assigned to an arm because of substantial differences in years of smoking cessation counseling.

\section{Individual counseling before the quit day}

The main focus of the first session will be assessing each participant's readiness for smoking cessation and setting the target quit day accordingly. The day will be usually set between the third and fifth sessions. Pre-quit sessions will be focused on preparing the participants for the quit day, which include counseling to delay smoking the first cigarette at least 30 minutes after awakening and expanding smokingfree areas inside the house until complete smoking ban will be established at least a week before the target quit day. As a form of knowledge development, the effects of smoking on people with HIV will also be highlighted during the first session. The second session will be geared toward explaining the neurobiologic changes associated with nicotine addiction and the immediate health benefits of quitting. The session (usually the third or the fourth one) right before the quit day will be focused on explaining the underlying treatment mechanism of transdermal nicotine patches. During the session, correct usage of nicotine patches, their possible side effects, and how to manage the side effects will be educated. Skills training for situational smoking temptations will be provided with role plays, so that participants can learn the coping strategies that are known to be effective for avoiding lapses and relapses. 
Table 2 Intervention components of each session

\begin{tabular}{|c|c|c|}
\hline $\begin{array}{l}\text { Session } \\
\text { number }\end{array}$ & Agenda & Intervention components \\
\hline I & $\begin{array}{l}\text { Assessment and } \\
\text { planning }\end{array}$ & $\begin{array}{l}\text { Assess the importance of quitting and confidence in quitting } \\
\text { Select the target quit day } \\
\text { Discuss how to change one's smoking pattern toward quitting } \\
\text { Assign the homework of an hourly smoking log } \\
\text { Educate what smoking does to people with HIV } \\
\text { Instill hope for smoking cessation }\end{array}$ \\
\hline 2 & $\begin{array}{l}\text { Health benefits of } \\
\text { quitting }\end{array}$ & $\begin{array}{l}\text { Discuss the immediate health benefits of quitting } \\
\text { Inform high morbidity and mortality of AIDS-related cancers among women who smoke compared to } \\
\text { those who do not smoke } \\
\text { Encourage the participant to watch CDC's video clips of former smokers: smoking and HIV } \\
\text { Explain the neurobiologic changes in the brain associated with nicotine addiction }\end{array}$ \\
\hline 3 & $\begin{array}{l}\text { Quit day } \\
\text { preparation }\end{array}$ & $\begin{array}{l}\text { Explain the underlying mechanism, effects, and side effects of nicotine patches and how to manage the side } \\
\text { effects } \\
\text { Counsel behavior changes in preparation for the quit day } \\
\text { Explain the possible drug-to-drug interactions between nicotine patches and HIV medications }\end{array}$ \\
\hline 4 & $\begin{array}{l}\text { First post-quit } \\
\text { assessment }\end{array}$ & $\begin{array}{l}\text { Assess nicotine withdrawal symptoms, lapse/relapse, adherence to nicotine patches, and any side effects of } \\
\text { nicotine patches } \\
\text { Educate proper management of patch problems } \\
\text { Counsel behavioral coping strategies for nicotine withdrawal symptoms }\end{array}$ \\
\hline 5 & Lapses and relapses & $\begin{array}{l}\text { Assess nicotine withdrawal symptoms and lapse/relapse } \\
\text { Discuss helpful cessation strategies including 4Ds (delay, deep breathing, drink water, and distract) } \\
\text { Counsel how to manage smoking tempting situations }\end{array}$ \\
\hline 6 & $\begin{array}{l}\text { Stress and coping } \\
\text { skills }\end{array}$ & $\begin{array}{l}\text { Assess nicotine withdrawal symptoms and lapse/relapse } \\
\text { Counsel to understand the effects of negative cognitions and moods (e.g., depression and anxiety) on } \\
\text { relapse } \\
\text { Discuss positive coping skills } \\
\text { Encourage exercise and healthy living lifestyle change }\end{array}$ \\
\hline 7 & Medication adherence & $\begin{array}{l}\text { Assess medication adherence } \\
\text { Discuss any positive changes experienced in the body } \\
\text { Explain the importance of adherence to nicotine patches } \\
\text { Remind the dosage decrease in nicotine patches (from step I, } 21 \mathrm{mg} \text { to step } 2,14 \mathrm{mg} \text { ) }\end{array}$ \\
\hline 8 & Relapse prevention & $\begin{array}{l}\text { Discuss the strategies to avoid lapses/relapses at high-risk situations (e.g., meeting a friend with whom the } \\
\text { participant used to smoke) } \\
\text { Revisit the importance of medication adherence } \\
\text { Encourage to reframe self as an ex-smoker } \\
\text { Encourage to participate in various group activities (e.g., nicotine anonymous telephone group and gym } \\
\text { exercise group) }\end{array}$ \\
\hline
\end{tabular}

Abbreviations: AIDS, acquired immune deficiency syndrome; CDC, Centers for Disease Control and Prevention; HIV, human immunodeficiency virus.

\section{Individual counseling after the quit day}

Post-quit sessions will vary by individual needs depending on abstinence status and the severity of nicotine withdrawal symptoms. Thus, the number of cigarettes smoked for the past 7 days will be assessed at each post-quit session using the 7-day Timeline Followback Scale. ${ }^{39}$ Minnesota Nicotine Withdrawal Scale will be assessed prior to counseling at each post-quit session and participants will be counseled accordingly, depending on the severity of nicotine withdrawal symptoms. ${ }^{40}$ Participants will be counseled to utilize the 4Ds (deep breathing, drink water, distract, and delay) behavioral strategies when they experience nicotine withdrawal symptoms. ${ }^{38}$ For example, participants are guided to make a list of activities that they can easily engage in to distract themselves from craving for cigarettes. Those who are not able to quit on the quit day or relapse to smoking after days of abstinence will be encouraged to make another quit attempt. Participants who have severe nicotine dependence and are struggling with nicotine withdrawal symptoms will be counseled to use short-acting nicotine replacement products such as nicotine gums or nicotine lozenges along with nicotine patches. Yet, as per the study protocol, only nicotine patches will be provided in this study. Those who want to use additional NRT products will be encouraged to purchase them over the counter and report the use to the counselor.

\section{Nicotine replacement therapy}

Participants in both arms will receive a free supply of nicotine patches by post office mail at two separate occasions: first 4-week supplies of $21 \mathrm{mg}$ and then 2-week supplies of each 14 and $7 \mathrm{mg}$ together. Those who smoke between 
five and nine cigarettes will receive $14 \mathrm{mg}$ for 6 weeks and then $7 \mathrm{mg}$ for 2 weeks. Adherence to nicotine patches will be monitored by recording the number of patches that they have used in the past 7 days. Participants in the telephone arm will be simply asked to provide the number, whereas those in the video arm will be asked to show the patches that they have used for the past week. Clinical Practice Guidelines suggest that all patients attempting to quit should be encouraged to use effective pharmacotherapies for smoking cessation. ${ }^{38}$ Nicotine patches were selected because they are most convenient to use among the NRT products. A large proportion of WLHIV who smoke may be likely to be depressed and receive treatment for the condition. ${ }^{41-43}$ Therefore, varenicline or bupropion sustained-release were not selected in order to avoid possible drug-to-drug interactions. Prior to receiving nicotine patches, the participants will be instructed as to the correct usage and possible side effects of nicotine patches, and which side effects that they should report immediately.

\section{Therapist training and supervision}

The first author of this study is a tobacco treatment specialist who has $>10$ years of experience with smoking cessation counseling. She trained a female graduate student who also will provide cessation counseling. The graduate student had 20 hours of intensive training related to the intervention. The training also included role-playing scenarios of common problems. Supervision of the student will be done weekly during the first 2 months and will be continued biweekly throughout the study. All therapy sessions will be audiotaped and one-third of them will be randomly selected for feasibility assessment.

\section{Participant incentives}

Participants in both arms will receive a gift card by postage mail when they complete baseline and follow-up assessments. The value of gift cards will vary from $\$ 30$ at baseline to $\$ 25$ at each post-quit follow-up. They will receive an additional gift card worth $\$ 25$ when they perform a home-based salivary cotinine test at each 3- and 6-month follow-up.

\section{Study measures}

The primary outcome of the study will be 6-month prolonged abstinence, that is, continuous abstinence from the quit day except for the first 2-week grace period. ${ }^{44}$ Seven-day point prevalence abstinence, meaning having not smoked a single puff for the past 7 days, will be assessed at each 1, 3, and 6 months post-quit as a secondary outcome. In addition to self-report, home-based salivary cotinine test will be done at 3- and 6-month follow-ups using a NicAlert ${ }^{\circledR}$ test strip (Nymox Pharmaceutical Corporation, Hasbrouck Heights, NJ, USA). Abstinence will be assessed using a combination of self-report and biochemical measure. The NicAlert test strip is a semi-quantitative measure and displays seven zones with a range of cotinine levels from 0 (cotinine concentration $0-10 \mathrm{ng} / \mathrm{mL}$ ) to 6 (cotinine concentration $\geq 2,000 \mathrm{ng} / \mathrm{mL}$ ). The standard salivary cotinine concentration cutoff for smoking is $14 \mathrm{ng} / \mathrm{mL}$, and hence, cotinine levels higher than 0 (cotinine concentration $<10 \mathrm{ng} / \mathrm{mL}$ ) are indicative of smoking. ${ }^{45}$ Compared with gas chromatography, the NicAlert had a specificity of $95 \%$ (95\% confidence interval [CI; 89\%, 100\%]), sensitivity of $93 \%(95 \%$ CI [ $85 \%$, $100 \%])$, positive predictive value of $95 \%(95 \%$ CI $[89 \%$, $100 \%])$, and a negative predictive value of $93 \%(95 \% \mathrm{CI}$ $[86 \%, 100 \%]) .{ }^{46}$

At baseline, the following information will be obtained as part of demographic characteristics: race, ethnicity, age, marital status, employment, and years of education. Information on year of HIV diagnosis, current CD4 cell count, and viral load count will be obtained from selfreport. Smoking-related variables such as age at smoking onset, the number of cigarettes smoked per day on average, and smoking-related stigma will be assessed. Key study variables will be assessed using the following measures: HAART adherence, HIV-related sigma, Fagerström Test for Nicotine Dependence, Self-efficacy in Resisting Smoking Temptation, Center for Epidemiologic Studies-Depression Scale, Generalized Anxiety Disorder 7-item scale, and General Client Satisfaction Questionnaire. ${ }^{46-53}$ These measures were selected to examine whether they would moderate or mediate the effect of the smoking cessation intervention. For example, the stigma measure assesses the degree of personalized (or self) stigma, HIV disclosure concerns, negative self-image, and concern with public attitudes toward people with HIV, which may be related to health promotion and wellness efforts, such as smoking cessation. There is evidence that women perceive more HIV-related stigma than men, and those who have high perceived HIVrelated stigma are less likely to disclose their HIV status to others, to seek treatment, and to adhere successfully to their medication. " "Self-efficacy" has been identified as the only variable that significantly mediates the effect of a smoking cessation intervention on abstinence among people living with HIV. ${ }^{25}$ There is ample evidence that people who are depressed and anxious are less likely to succeed in quitting smoking. ${ }^{54-56}$

Nicotine withdrawal symptoms will be assessed using the Minnesota Nicotine Withdrawal Scale prior to counseling at 
each post-quit session of the first 4 weeks. ${ }^{40}$ Self-efficacy will be assessed at each follow-up. Fagerström Test for Nicotine Dependence score will be assessed at 1-, 3-, and 6-month follow-ups for those who continued to smoke daily after the target quit day. In addition, depression and anxiety will be assessed at 3- and 6-month follow-ups and the scores will be compared with the baseline scores.

\section{Data collection}

All participants who are screened as eligible will receive a brown envelope enclosed with a cover letter, informed consent form, baseline questionnaire, and self-addressed stamped envelope for the return of the consent form and the research questionnaire. The baseline data will be collected in the format of paper and pencil self-administration. Follow-up assessments will be done by telephone call at 1 month postquit and by video call at 3 and 6 months post-quit. A research staff who is not the therapist of the participant will conduct the interview. The person will be, however, not blind to the intervention condition (i.e., group allocation).

All participants, irrespective of their self-reported abstinence, will receive a NicAlert test kit by postage mail right before 3- and 6-month follow-up assessments. Participants will conduct the test at home following the step-by-step instructions provided by a research staff. The test result will be available when the blue band of the test strip disappears, which usually takes 20-30 minutes. The whole procedure of the test will be closely monitored through video call by the staff person. Each participant will be asked to take a photo of the test strip right after the reading and send it to the staff person. The photo was forwarded to three independent readers who are blind to the intervention condition. If the readings are different from one another, the result will be determined by consensus.

\section{Data analysis}

Data will be reviewed prior to data entry and entered by a research coordinator, which will be double-checked for errors or completeness by a third person. Data will be analyzed using Stata 14 (Stata Corp LP, College Station, TX, USA). Intention-to-treat analytic strategy will be used for cessation outcomes with missing values. The primary outcome of the study will be a 6-month prolonged abstinence. Its secondary outcomes will include 7-day point prevalence abstinence at each follow-up (1, 3, and 6 months post-quit), time to the first lapse, time to relapse, recovery rates from smoking relapse as well as changes in self-efficacy, depressive symptoms, and anxiety symptoms between the two treatment conditions and over time (baseline and 3- and 6-month follow-ups).
Specific aim I: test the feasibility and acceptability of a videoconferencing smoking cessation intervention for women with HIV

Recruitment and retention rates will be recorded per month throughout the study period. Any barriers to the recruitment and retention will be explored. Reasons for those who are eligible but decline to participate in the study will be recorded. Attrition rates will be compared by intervention condition and abstinence status at each follow-up. All participants will be asked to complete an exit survey, rating their overall satisfaction with the intervention that they have received.

\section{Specific aim 2: establish a preliminary effect size} of the videoconferencing smoking cessation intervention on 6-month prolonged abstinence compared to the telephone-based smoking cessation intervention

The balance of participants' baseline demographics and smoking behavior between the two treatment conditions (videoconferencing vs. telephone counseling) will be evaluated using Mann-Whitney $U$ tests or independent two-sample $t$-tests for continuous variables and the $\chi^{2}$ tests for categorical variables. Contingency analysis with $\chi^{2}$ test will be used to examine differences in the 6-month prolonged and 7-day point prevalence abstinence at each follow-up between the two arms. Survival analyses will be conducted to examine the relationship between the two arms and abstinence using the Kaplan-Meier survival plot and Cox proportional hazards model for possible covariates such as nicotine dependence and self-efficacy. Based on the intention-to-treat analysis, those who are missing at follow-ups will be treated as smoking. Participants who self-report abstinence but yield a positive result (cotinine concentration $\geq 10 \mathrm{ng} / \mathrm{mL}$ ) or refuse to do the salivary cotinine test for any reasons will be all treated as smoking. An effect size will be calculated by comparing the 6-month prolonged abstinence rates between the two arms.

Specific aim 3: examine the feasibility of a homebased salivary cotinine test by a video call for the verification of self-reported abstinence

The feasibility will be assessed by calculating how many participants out of the total sample are able to do the home-based salivary cotinine test. Inter-rater agreement among the readers of test results will be assessed using Cohen's Kappa statistics.

\section{Discussion}

To the best of our knowledge, this is the first study testing the acceptability and feasibility of a videoconferencing smoking cessation intervention for WLHIV. Most WLHIV 
face several challenges in getting the health care services and information that they need, including socioeconomic and structural barriers, such as poverty, cultural inequities, and sexual violence. ${ }^{57}$ This study will determine whether WLHIV are able to participate in a telephone-based smoking cessation intervention that does not provide a prepaid cell phone. Smoking cessation studies conducted with people living with HIV usually provided a prepaid cell phone for telephone counseling or text message. ${ }^{16,17,58}$ Older women may have more difficulty operating a video call web application. It was reported that older adults ( $50-65$ years) showed a lower performance than younger adults (20-35 years) when handling the interface of a mobile phone..$^{59}$ The study conducted with Korean American women also reported that those older than 50 years had difficulty operating a video call web application. ${ }^{32}$

This study is a pilot clinical trial with the target sample 50 , which is not adequately powered. It will help researchers estimate an effect size for future larger studies. Although statistically insignificant, cotinine-confirmed abstinence rate at 3 months post-quit was approximately $10 \%$ higher among Korean American women who received a videoconferencing cessation intervention than among those who received a telephone counseling one. ${ }^{32}$ We will determine from this study whether it is worthwhile to pursue videoconferencing smoking cessation interventions as an adjunct to telephone counseling interventions such as quitline service for women who tend to have lower success rates with the service. . $^{23-27,32}$

The study will also test the feasibility of a home-based salivary cotinine test using a NicAlert test strip. The NicAlert test is relatively cost effective compared to $\mathrm{CO}$ breath test. The test strips cost $\$ 12-15$ apiece, whereas CO meters generally cost about $\$ 600-1,200$ each. Although a mobile phone-based CO meter had been pilot-tested, it is not yet commercially available. ${ }^{60}$ Breath CO test is generally less reliable than salivary cotinine test because breath $\mathrm{CO}$ output is largely affected by the speed of emptying the lung. ${ }^{61}$ For example, when heavy smokers switched from exhaling slow to exhaling fast, they had an approximately $30 \%$ reduction in $\mathrm{CO}$ output. ${ }^{61}$ Of note, in a previous study conducted with Korean American women, 3/20 women who self-reported abstinence did not conduct the test. One of them was excluded due to the use of over-the-counter nicotine patches and the other two refused the test. ${ }^{32}$ The present study will provide an additional incentive worth $\$ 25$ for participation in the homebased salivary cotinine test, which may facilitate participants in this study to conduct the salivary cotinine test and validate their self-reported abstinence.

\section{Acknowledgment}

The study is partially supported by Joseph P Healey Research Grant at the University of Massachusetts Boston given to Drs. Kim and DeMarco. The content of this article is solely the responsibility of the authors and in no way reflects the official policy of the university.

\section{Disclosure}

The authors report no conflicts of interest in this work.

\section{References}

1. Pratt RJ. HIV \& AIDS: A Foundation for Nursing and Health Care Practice. 5th ed. London, UK: Oxford University Press; 1998.

2. Campbell C. Women, Families \& HIV/AIDS: A Sociological Perspective on the Epidemic in America. Cambridge, UK: Cambridge University Press; 1999.

3. Gennrich D. The Church in an HIV Positive World. South Africa: Cluster Publications; 2004.

4. Boily MC, Baggaley RF, Wang L, et al. Heterosexual risk of HIV-1 infection per sexual act: systematic review and meta-analysis of observational studies. Lancet Infect Dis. 2009;9(2):118-129.

5. CDC.gov [homepage on the Internet]. HIV surveillance report. Atlanta/ GA: Center for Disease Control and Prevention Online resource [updated January 3, 2017]. Available from: https://www.cdc.gov/hiv/ library/reports/hiv-surveillance.html. Accessed January 12, 2017.

6. Kohli R, Lo Y, Homel P, et al. Bacterial pneumonia, HIV therapy, and disease progression among HIV-infected women in the HIV epidemiologic research (HER) study. Clin Infect Dis. 2006;43:90-98.

7. Palella FJ, Baker RK, Moorman AC, et al. Mortality in the highly antiretroviral therapy era: changing causes of death and disease in the HIV outpatient study. J Acquir Immune Defic Syndr. 2006;43(1):27-34.

8. Lifson AR, Neuhaus J, Arribas JR, et al. Smoking related health risks among persons with HIV in the strategies for management of antiretroviral therapy clinical trial. Am J Public Health Res. 2010;100(10):1896-1903.

9. Madeddu G, Laura FM, Stella MM. Bacterial community-acquired pneumonia in HIV-infected patients. Curr Opin Pulm Med. 2010;16(3): 201-207.

10. Lifson AR, Lando HA. Smoking and HIV: prevalence, health risks, and cessation strategies. Curr HIV/AIDS Rep. 2012;9(3):223-230.

11. Madeddu G, Fois AG, Calia GM, et al. Chronic obstructive pulmonary disease: an emerging comorbidity in HIV-infected patients in the HAART era? Infection. 2013;41(2):347-353.

12. Attia EF McGinnis KA, Feemster LC, et al. Association of COPD with risk for pulmonary infections requiring hospitalization in HIV-infected veterans. J Acquir Immune Defic Syndr. 2015;70(3):280-288.

13. Mdodo R, Frazier EL, Dube SR, et al. Cigarette smoking prevalence among adults with HIV compared with the general adult population in the United States: cross-sectional surveys. Ann Intern Med. 2015; 162(5):335-344.

14. Pacek LR, Harrell PT, Martins SS. Cigarette smoking and drug use among a nationally representative sample of HIV-positive individuals. Am J Addict. 2014;23(6):582-590.

15. Moscou-Jackson G, Commodore-Mensah Y, Farley J, DiGiacomo M. Smoking-cessation interventions in people living with HIV infection: a systematic review. J Assoc Nurses AIDS Care. 2014;25(1):32-45.

16. Vidrine DJ, Marks RM, Arduino RC, Gritz ER. Efficacy of cell phonedelivered smoking cessation counseling for persons living with HIV/ AIDS: 3-month outcomes. Nicotine Tob Res. 2012;14(1):106-110.

17. Gritz ER, Danysh HE, Fletcher FE, et al. Long-term outcomes of a cell phone-delivered intervention for smokers living with HIV/AIDS. Clin Res Infect Dis. 2013;57(4):608-615.

18. Stanton CA, Papandonatos GD, Shuter J, et al. Outcomes of a tailored intervention for cigarette smoking cessation among latinos living with HIV/AIDS. Nicotine Tob Res. 2015;17(8):975-982. 
19. Humfleet FL, Hall SM, Delucchi KL, Dilley JW. A randomized clinical trial of smoking cessation treatments provided in HIV clinical care settings. Nicotine Tob Res. 2013;15(8):1436-1445.

20. Hessol NA, Weber KM, D'Souza G, et al. Smoking cessation and recidivism in the women's interagency human immunodeficiency virus study. Am J Prev Med. 2014;47(1):53-69.

21. Shiffman S, Paton SM. Individual differences in smoking: gender and nicotine addiction. Nicotine Tob Res. 1999;1 (Suppl 2):S153-S157.

22. Allen AM, Scheuermann TS, Nollen N, Hatsukami D, Ahluwalia JS. Gender differences in smoking behavior and dependence motives among daily and nondaily smokers. Nicotine Tob Res. 2016;18(6):1408-1413.

23. Wetter DW, Kenford SL, Smith SS, Fiore MC, Jorenby DE, Baker TB. Gender differences in smoking cessation. J Consult Clin Psychol. 1999;67(4):555-562.

24. Bohadana A, Nilsson F, Rasmussen T, MartinetY. Gender differences in quit rates following smoking cessation with combination nicotine therapy: influence of baseline smoking behavior. Nicotine Tob Res. 2003;5(1):111-116.

25. Cepeda-Benito A, Reynoso JT, Erath S. Meta-analysis of the efficacy of nicotine replacement therapy for smoking cessation: differences between men and women. J Consult Clin Psychol. 2004;72(4):712-722.

26. Perkins KA, Scott J. Sex differences in long-term smoking cessation rates due to nicotine patch. Nicotine Tob Res. 2008;10(7):1245-1250.

27. Smith PH, Kasza KA, Hyland A, et al. Gender differences in medication use and cigarette smoking cessation: results from the International Tobacco Control Four Country Survey. Nicotine Tob Res. 2015;17(4):463-472.

28. McKee SA, O'Malley SS, Salovey P, Krishnan-Sarin S, Mazure CM. Perceived risks and benefits of smoking cessation: gender-specific predictors of motivation and treatment outcome. Addict Behav. 2005; 30(3):423-435.

29. LeventhalAM, WatersAJ, Boyd S, MoolchanET,Lerman C, PickworthWB. Gender differences in acute tobacco withdrawal: effects on subjective, cognitive, and physiological measures. Exp Clin Psychopharmcol. 2007; 15(1):21-36.

30. Xu J, Azizian A, Monterosso J, et al. Gender effects on mood and cigarette craving during early abstinence and resumption of smoking. Nicotine Tob Res. 2008;10(11):1653-1661.

31. Weinberger AH, Pilver CE, Desai RA, Mazure CM, McKee SA. The relationship of major depressive disorder and gender to changes in smoking for current and former smokers: longitudinal evaluation in the U.S. population. Addiction. 2012;107(10):1847-1856.

32. Kim SS, Sitthisongkram S, Bernstein K, Fang H, Choi W, Ziedonis D. A randomized controlled trial of a videoconferencing smoking cessation intervention for Korean American women: preliminary findings. Int $J$ Womens Health. 2016;8:453-462.

33. Richter KP, Shireman TI, Ellerbeck EF, et al. Comparative and cost effectiveness of telemedicine versus telephone counseling for smoking cessation. J Med Internet Res. 2015;17(5):e113.

34. Carlson LE, Lounsberry JJ, Maciejewski O, Wright K, CollacuttV.Taenzer P. Telehealth-delivered group smoking cessation for rural and urban participants: feasibility and cessation rates. Addict Behav. 2012;37(1):108-114.

35. Curry LE, Richardson A, Xiao H, Niaura RS. Nondisclosure of smoking status to health care providers among current and former smokers in the United States. Health Educ Behav. 2013;40(3):266-273.

36. Hertzog MA. Considerations in determining sample size for pilot studies. Res Nurs Health. 2008;31(2):180-191.

37. Bandura A. Social Foundations of Thought and Action: A Social Cognitive Theory. Englewood Cliffs, NJ: Prentice-Hall, Inc; 1986.

38. Fiore M, Jaen CR, Baker T, et al. Treating Tobacco Use and Dependence: 2008 Update. Rockville, MD: US Department of Health and Human Services; 2008.

39. Sobell LC, Sobell MB. Alcohol consumption measures. In: Allen JP, Wilson VB, editors. Assessing Alcohol Problems: A Guide for Clinicians and Researchers. Bethesda, MD: National Institute on Alcohol Abuse \& Alcoholism; 2003:75-99.

40. Hughes JR, Hatsukami DK. Signs and symptoms of tobacco withdrawal. Arch Gen Psychiatry. 1986;43(3):289-294.
41. Balfour L, Wiebe SA, Cameron WD, et al. An HIV-tailored quit-smoking counselling pilot intervention targeting depressive symptoms plus nicotine replacement therapy. AIDS Care. 2017;29(1):24-31.

42. Gardner LI, Marks G, Shahani L, et al. Assessing efficacy of a retentionin-care intervention among HIV patients with depression, anxiety, heavy alcohol consumption and illicit drug use. AIDS. 2016;30(7):1111-1119.

43. Stewart DW, Jones GN, Minor KS. Smoking, depression, and gender in low-income African Americans with HIV/AIDS. Behav Med. 2011; 37(3):77-80.

44. Hughes JR, Keely JP, Niaura RS, Ossip-Klein DJ, Richmond RL, Swan GE. Measures of abstinence in clinical trials: issues and recommendations. Nicotine Tob Res. 2003;5(1):13-25.

45. Cooke F, Bullen C, Whittaker R, McRobbie H, Chen M-H, Walker N. Diagnostic accuracy of NicAlert cotinine test strips in saliva for verifying smoking status. Nicotine Tob Res. 2008;10(4):607-612.

46. Mannheimer S, Mukherjee R, Hirschhorn L, et al. The CASE adherence index: a novel method for measuring adherence to antiretroviral therapy. AIDS Care. 2006;18(7):853-861.

47. Berger BE, Ferrans CE, Lashley FR. Measuring stigma in people with HIV: psychometric assessment of the HIV stigma scale. Res Nurs Health. 2001;24(6):518-529.

48. Heatherton TF, Kozlowski LT, Frecker RC, Fagerstrom KO. The Fagerström test for nicotine dependence: a revision of the Fagerstrom Tolerance Questionnaire. Br J Addict. 1991;86(9):1119-1127.

49. Fagerström, KO. Determinants of tobacco use and renaming the FTND to the Fagerström Test for cigarette dependence. Nicotine Tob Res. 2012; 14(1):75-78

50. Velicer WF, DiClemente CC, Rossi JS, Prochaska JO. Relapse situations and self-efficacy: an integrative model. Addict Behav. 1990;15(3): 271-283.

51. Radloff LS. The CES-D scale a self-report depression scale for research in the general population. Appl Psychol Meas. 1977;1(3):385-401.

52. Spitzer RL, Kroenke K, Williams JBW, Lowe B. A brief measure for assessing generalized anxiety disorder (The GAD-7). Arch Intern Med. 2006;166(10):1092-1097.

53. Larsen DL, Attkisson CC, Hargreaves WA, Nguyen TD. Assessment of client/patient satisfaction: development of a general scale. Eval Program Plann. 1979;2(3):197-207.

54. Johnson KA, Stewart S, Rosenfield D, Steeves D, Zvolensky MJ. Prospective evaluation of the effects of anxiety sensitivity and state anxiety in predicting acute nicotine withdrawal symptoms during smoking cessation. Psychol Addict Behav. 2012;26(2):289-297.

55. Leventhal AM, Ameringer KJ, Osborn E, Zvolensky MJ, Langdon KJ. Anxiety and depressive symptoms and affective patterns of tobacco withdrawal. Drug Alcohol Depend. 2013;133(2):324-329.

56. Pomerleau OF, Pomerleau CS, Mehringer AM, Snedecor SM, Ninowski R, Sen A. Nicotine dependence, depression, and gender: characterizing phenotypes based on withdrawal discomfort, response to smoking, and ability to abstain. Nicotine Tob Res. 2005;7(1):91-102.

57. KFF.org [homepage on the Internet]. Menlo Park: the Kaiser Family Foundation. Women and HIV/AIDS in the United States. Available from: http://kff.org/hivaids/fact-sheet/women-and-hivaids-in-the-unitedstates/. Accessed March 6, 2014.

58. Tseng T-Y, Krebs P, Schoenthaler A, et al. Combining text messaging and telephone counseling to increase varenicline adherence and smoking abstinence among cigarette smokers living with HIV: a randomized controlled study. AIDS Behav. Epub 2016 Sep 7.

59. Ziefle M, Bay S. How older adults meet complexity: aging effects on the usability of different mobile phones. Behav Inf Technol. 2005;24(5): 375-389.

60. Meredith SE, Robinson A, Erb P, et al. A mobile-phone-based breath carbon monoxide meter to detect cigarette smoking. Nicotine Tob Res. 2014;16(6):766-773.

61. Raiff BR, Faix C, Turturici M, Dallery J. Breath carbon monoxide output is affected by speed of emptying the lungs: implications for laboratory and smoking cessation research. Nicotine Tob Res. 2010;12(8):834-838. 


\section{Publish your work in this journal}

The Open Access Journal of Clinical Trials is an international, peerreviewed, open access journal publishing original research, reports, editorials, reviews and commentaries on all aspects of clinical trial design, management, legal, ethical and regulatory issues, case record form design, data collection, quality assurance and data auditing

methodologies. The manuscript management system is completely online and includes a very quick and fair peer-review system, which is all easy to use. Visit http://www.dovepress.com/testimonials.php to read real quotes from published authors.

Submit your manuscript here: https://www.dovepress.com/open-access-journal-of-clinical-trials-journal 